\title{
Hydraulic Geometry of a Small Tidal Estuary
}

GEOLOGICAL SURVEY PROFESSIONAL PAPER 422-B
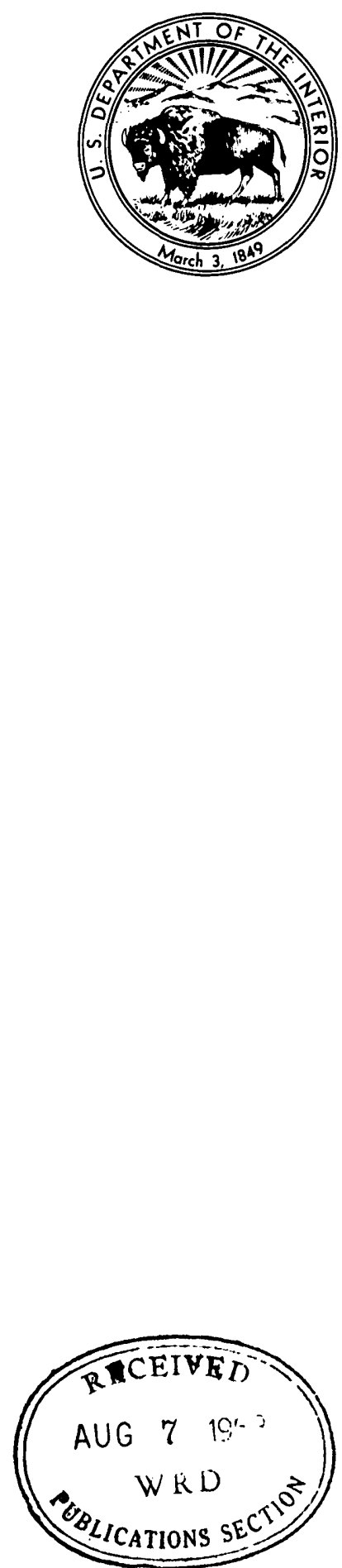



\section{Hydraulic Geometry of a Small Tidal Estuary}

By ROBERT M. MYRICK and LUNA B. LEOPOLD

PHYSIOGRAPHIC AND HYDRAULIC STUDIES OF RIVERS

GEOLOGICAL SURVEY PROFESIONAL PAPER 422-B

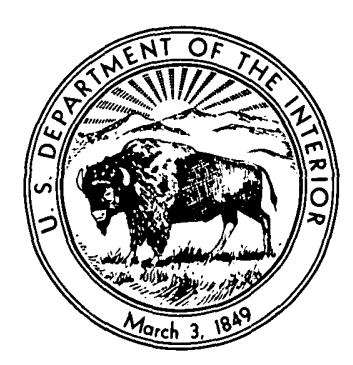

UNITED STATES GOVERNMENT PRINTING OFFICE, WASHINGTON : 1963 



\title{
PHYSIOGRAPHIC AND HYDRAULIC STUDIES OF RIVERS
}

\section{HYDRAULIC GEOMETRY OF A SMALL TIDAL ESTUARY}

\author{
By Robert M. Myricis and Luna B. Leopold
}

\section{ABSTRACT}

A tidal channel in a marsh bordering the Potomac River near Alexandria, Va., was mapped, and current-meter measurements of discharge were made at various locations and at various stages in the tidal cycle. These measurements allowed analysis of the change of width, depth, and velocity with discharge at various cross sections and along the length of the channel.

There is also presented a theoretical development of some of these same relations based on hydraulic principles and on the assumption of a uniform distribution of energy and a minimum rate of work in the system as a whole.

The change of width, depth, and velocity with discharge downstream developed from the field data checked closely with the theoretically derived values.

The estuarine channel differs from a terrestrial one in that discharge at any section in an estuary varies depending on how the flow shaped the entire length of the channel between the point; in question and the main body of tidal water. The result is that a tidal channel changes more rapidly in width and less rapidly in depth as discharge changes downstream than does a terrestrial channel.

\section{INTRODUCTION}

The shape and characteristics of a river channel are believed to be determined and maintained by what has been called by irrigation engineers the dominant discharge. Whereas in an irrigation canal the usual or design discharge is ordinarily the modal flow, the designation of a dominant discharge in a river is not as easy. The effective discharge most influential in river morphology and thus equivalent to the dominant discharge of canals is believed to be the flow at bankfull stage. This view was strengthened by the findings of Wolman and Leopold (1957), and substantiated later by Nixon (1959), that the bankfull discharge has a recurrence interval of 1 to 2 years and is similar among rivers in quite different physiographic settings.

Wolman and Miller (1960).) extended and generalized this into a concept of effective force in geomorphology. The greatest amount of geomorphic work, they postulate, depends not only on the effectiveness of each single event but also on the frequency of the events of different mignitudes. The combination of effectiveness and frequency that was most influential in maintaining river channel form and pattern was the bankfull discharge.

A tidal estuary is, in a sense, merely one of the ex- tremes in the continuum of river channels. The channel system of an estuary bears some close similarities to that of a river system. It differs, however, in at least one extremely important respect and that is the frequency of the bankfull stage. If, as some investigators believe, the bankfull stage is the one that is most effective in the maintenance of a river channel and is equaled or exceeded once every year or two, one may ask why the channel system of a tidal estuary so much resembles a river network, despite the fact that bankfull stage is attained about twice a day. Observations and measurements of flow characteristics at different sections along a tidal estuary, particularly at bankfull stage, may help to illuminate the position of estuarine channel systems in the continuum of all natural channels.

The bankfull stage of a tidal estuary may be defined as the stage at which the water incipiently flows over the adjacent marshlands. Unlike other streams, an estuarine channel having no runoff from the uplands experiences zero velocity at the nadir of ebb tide. Velocity increases progressively as the water deepens but again becomes zero at the crest of flood tide. From this fact arises the question concerning how the hydraulic factors vary along the length of the channel. system. There is a collateral question concerning the relation of the bankfull stage to the effective force in channel formation and maintenance.

To understand the hydraulic geometry of estuaries better and to compare it with that of an upland channel, this preliminary investigation was undertaken.

There are other collateral questions concerning the differences and similarities between upland streams and tidal ones. For example, does the tidal channel exhibit alternations of shallows and deeps which in upland channels we have referred to as pools and riffles? Does the drainage network of the tidal system divide into tributaries of various sizes in such a manner that their lengths and numbers bear a logarithmic relation to stream order as in upland channels?

Some evidence on these points was obtained in this investigation, enough to suggest that further investigation would be lucrative. But on all the points studied, 
the present data are limited, and any generalizations we suggest on the basis of these data should be viewed as working hypotheses needing further proof.

We are grateful to Estella B. Leopold and Anne Davis for their work on the samples obtained for pollen analysis, to H. L. Svenson for notes on the taxonomy of plants in the study area, and to Alfred C. Redfield, for a review of the manuscript and permission to include some of his unpublished data.

\section{AREA OF INVESTIGATION}

Against the west bank of the Potomac River, nearly adjacent to the city of Alexandria, Va., there was until the winter of 1960 a small area of tidal marsh relatively undisturbed by construction or dredging. It can be seen in the location map of figure 1 that the southern of three estuarine channels carries away nearly all the surface runoff originating in the high ground adjacent to the marsh. The central of the three channels, called by us Wrecked Recorder Creek, drains no upland area and is the one studied. The marshland tributary to this channel has an area of about 120 acres. The marsh area and channels draining it receive water only as rain falling directly on the tributary marsh and as flow induced by tidal fluctuation. The water exchanged with the Potomac estuary is here quite fresh (not salty).

The size of the channel was such that it could be measured with relative ease. Where it enters the Potomac River, the channel width is about 170 feet. The total length of channel from mouth to the most distant headwater tributary is approximately 5,000 feet. A tide gage operated by the U.S. Coast and Geodetic Survey is slightly less than 2 miles upstream from the mouth of the channel system studied.

Cross sections were measured at six locations along the channel system, as will be described. The estuarine channel was 134 feet wide at the most downstream section and 18 feet wide at the uppermost section.

Tidal fluctuations affect the whole length of Chesapeake Bay, and tidewater ends at the foot of the steep reach where the Potomac River descends over the Fall Line in the vicinity of Washington, D.C. The tidal estuary studied is thus about 11 river miles downstream from the head of tidewater.

Fieldwork was carried on during late spring and summer of 1960 . Shortly thereafter, dredging operations for commercial gravel production destroyed the channel system.

\section{DESCRIPTION OF THE MARSH}

The marsh area appears uniformly flat to the eye. In early spring the dried vegetation has been bent over by snow, so that at low tide one can walk with ease over nearly the full unchanneled area. There are some small areas within the marsh on which timber is the primary cover. Though some of these timbered areas appear to have a slightly higher elevation than average for the marsh, other timber patches appear to be flooded regularly.

By midsummer the marsh vegetation is thick and green, standing at least knee high. The photographs in figure 2 show typical channels and vegetation in early summer.

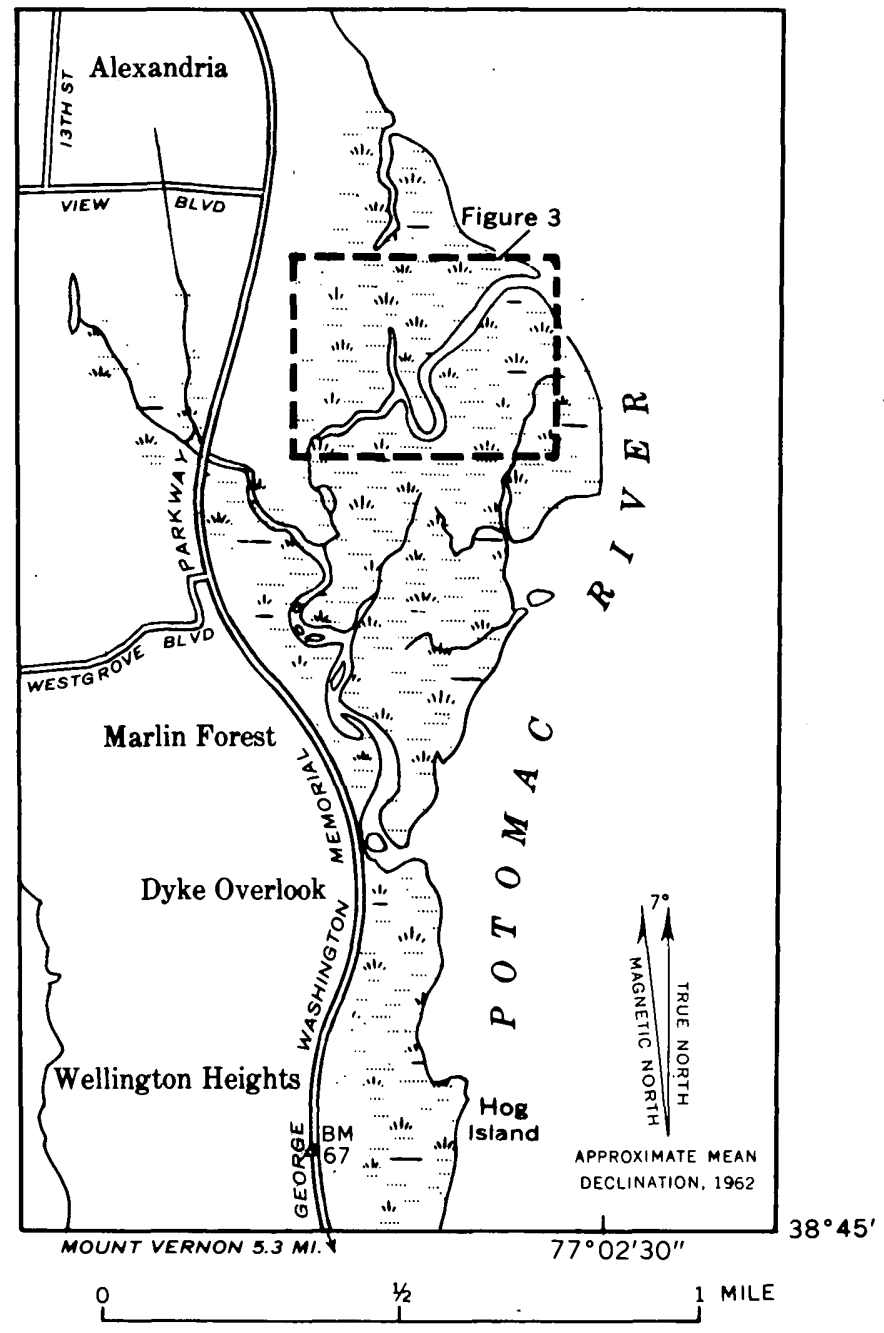

Figure 1.-Location map of Wrecked Recorder Creek, a tributary to the Potomac River, near Alexandria, Va.

Photographs of typical reaches of Wrecked Recorder Creek, June 10, 1960. $A$, Small tributary 400 feet below section $C$, right bank, stage 4.8 feet, falling. $B$, Section $F$, viewed from 20 feet downstream, stage 4.6 feet, falling. $C$, View looking downstream 250 feet upstream from section $D$, stage 4.6 feet, falling. $D$, Section $D$, looking upstream, stage 4.6 feet, falling. $E$, Left bank and entrance of small tributary at Iron Hulk Gage near section $A$, stage 4.92 feet, falling. $F$, View downstream to mouth of Wrecked Recorder Creek from position 200 feet downstream from section $B$; Potomac River barely vísible in clistance; stage 4.45 feet, falling. 

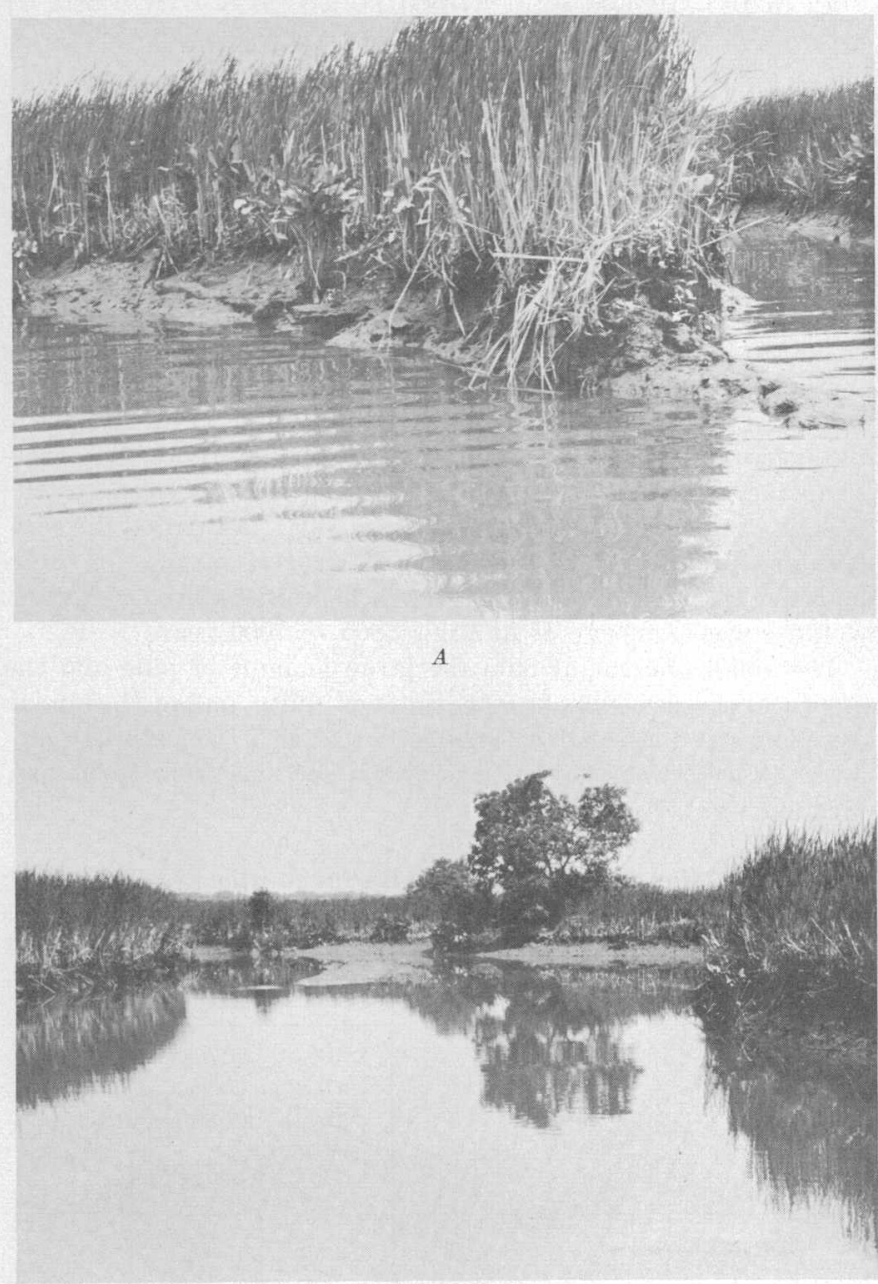

C

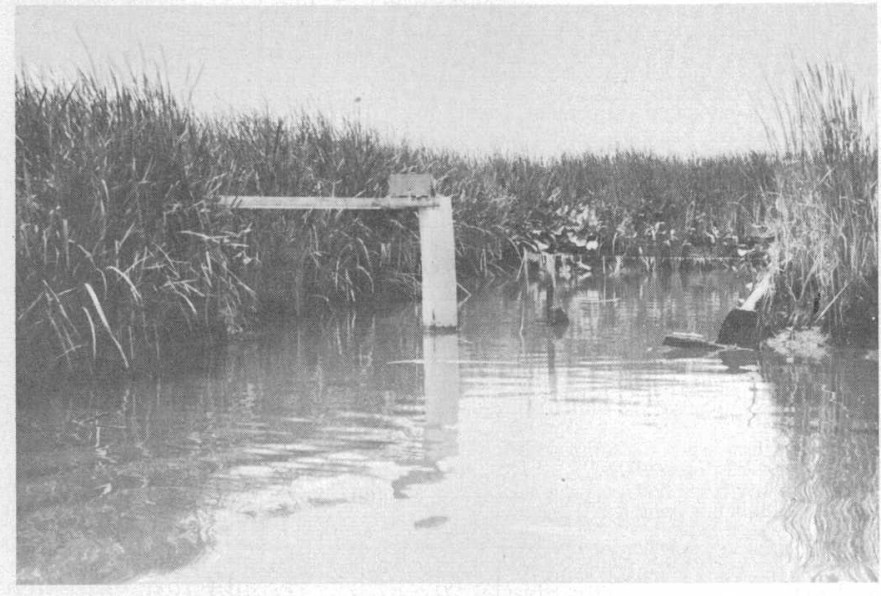

E
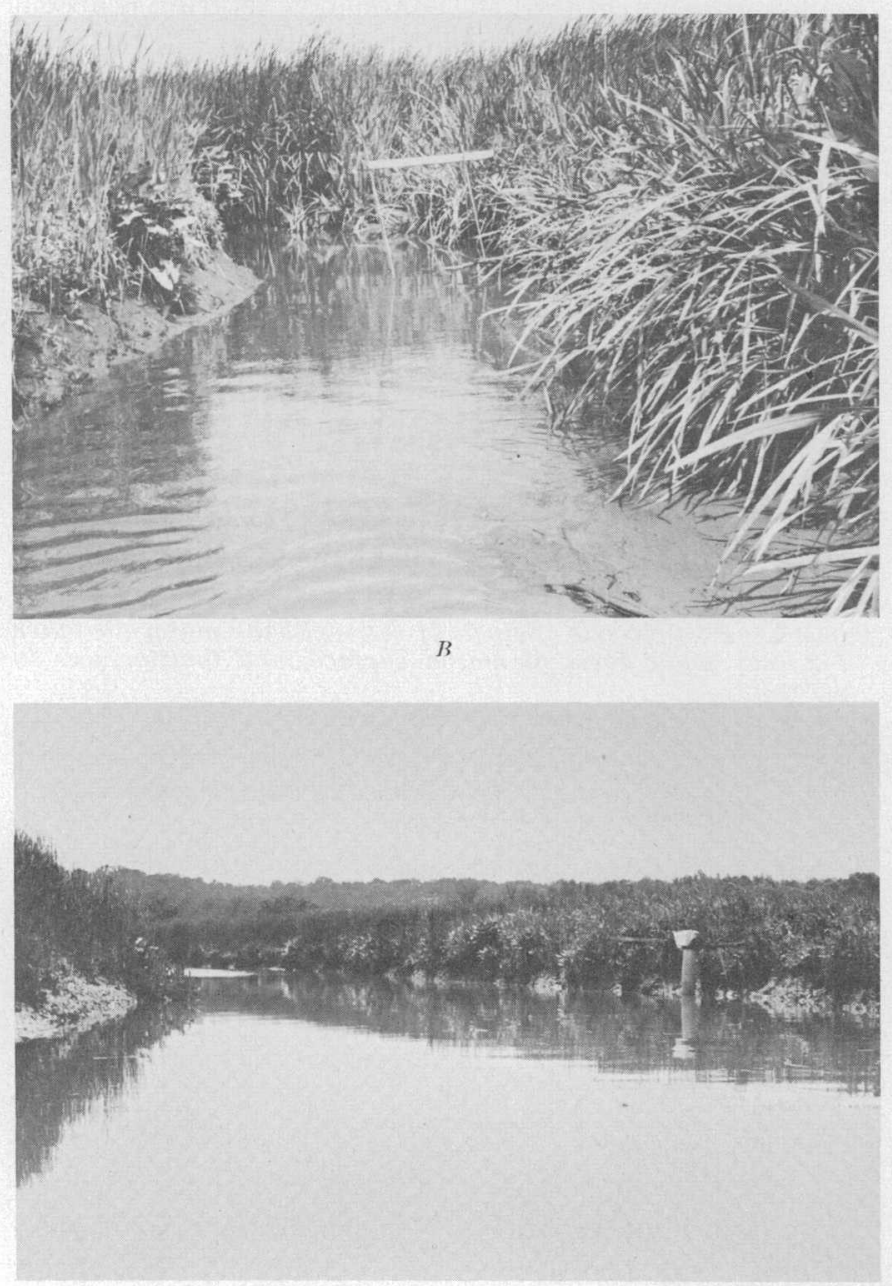

$D$

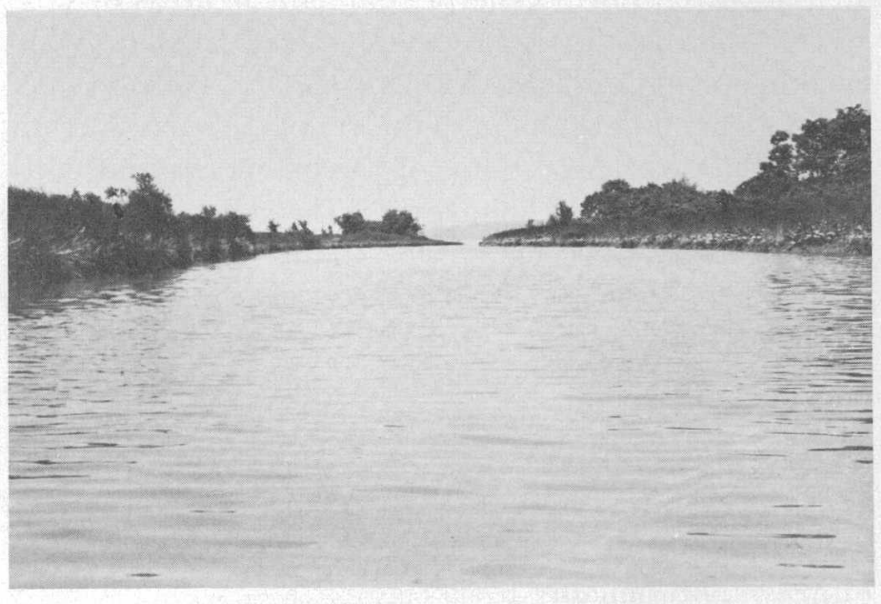


Along the margins of the channel, vegetation is absent below an elevation of 1 foot lower than the bankfull stage. At low tide there is exposed along the walls of nearly all channels a brown silt or clayey silt, containing some organic material. On the bottom along the centerline of the channel, the bed material is highly organic and black and has a texture not immediately obvious in the field.

Table 1 includes some typical data on particle-size distribution of samples taken at five of the established cross sections. The median size of these materials tended to be in the range from silt to fine sand. The table also shows the percentage of organic matter in the sample as determined from ignition-loss measurements.

\section{TABLE 1.-Particle-size analysis of channel-bank materials taken 1-2 feet below level of marsh surface, and ignition loss in percent}

[Data show percentage finer]

\begin{tabular}{|c|c|c|c|c|c|}
\hline \multirow{2}{*}{ Particle size (mm.) } & \multicolumn{5}{|c|}{ Section designation (sample from right bank) } \\
\hline & $A$ & $C$ & $D$ & $E$ & $\boldsymbol{F}$ \\
\hline $\begin{array}{l}1.0 \\
.50 \\
.25 \\
.0625 \\
.0312 \\
.0156 \\
.0078 \\
.0019\end{array}$ & $\begin{array}{r}100 \\
61 \\
54 \\
40 \\
35 \\
30 \\
24 \\
12 \\
5 \\
2 \\
\end{array}$ & $\begin{array}{r}100 \\
85 \\
73 \\
60 \\
59 \\
49 \\
41 \\
18 \\
5 \\
2 \\
\end{array}$ & $\begin{array}{r}100 \\
77 \\
59 \\
43 \\
40 \\
29 \\
22 \\
9 \\
3 \\
1 \\
\end{array}$ & $\begin{array}{r}100 \\
92 \\
78 \\
64 \\
62 \\
48 \\
36 \\
20 \\
12 \\
3 \\
\end{array}$ & $\begin{array}{r}100 \\
91 \\
75 \\
57 \\
48 \\
31 \\
28 \\
21 \\
11\end{array}$ \\
\hline Percent ignition loss at $700^{\circ} \mathrm{F}_{-.}$ & 11.3 & 10.6 & 12.7 & 10.9 & $\overline{13.0}$ \\
\hline
\end{tabular}

The dominant vegetation consists of cattails, Typha latifolia, and probably also T. angustifolia. Both species are to be expected in localities such as this, but $T$. angustifolia is in general dominant in areas of salty water. The basal part of some stands of T'ypha is whitened in spring, probably showing the limit of tide.

Another plant common to the area is the arrow arum, Peltandra virginica. Some of the plants are unusually luxuriant and might be taken for the yellow water lily, Nuphar advena, especially where partly submerged.

The trees growing in some areas slightly higher in elevation than average marsh surface include green ash, Fraxinus lanceolata, which is a common tree in such places in the tidewater region. The willows are probably Salix nigra, common along the Potomac in the Washington area.

Underlying most of the marsh area is a thick layer of gravel, presumably Pleistocene in age, which is being dredged for use in highway fills and other construction. The operators of the dredge stated that gravel layers occur 10 to 40 feet below the surface of the marsh.

A few samples were taken for pollen analysis at section $D$ at depths ranging from the marsh surface to 14 inches below it. These samples were brown silty clay which in the field appeared to be undisturbed by any recent lateral movement of the channel. A summary of the pollen analysis is presented in table 2 . The following interpretation of these samples is quoted from an unpublished report by Dr. Estella B. Leopold (written communication to authors concerning Paleontology and Stratigraphy Branch shipment WR-6011D).

The samples show a decrease of pine and a corresponding increase of hickory from the base to the top of the sampled section. These features, plus the presence of warm-temperate tree types and a small amount of spruce pollen represent an assemblage which is similar to that of the late pine zone or the postglacial pollen Zone B of Deevey (1939). Assuming the samples are postglacial rather than interglacial in age, an interpolation from a marsh section taken near Blackbird, Delaware, would suggest an age of at least 5000 to 7000 years B. P.

The small amount of oak, the large amount of pine and the presence of spruce make the samples quite unlike deciduous tree Zones C-1 through $\mathbf{C}-\mathbf{3}$ as represented at Blackbird, Delaware, as well as in several postglacial sections from Delaware, Virginia, and New Jersey.

TABLE 2.-Pollen analysis of samples taken along channel bank at section $D$

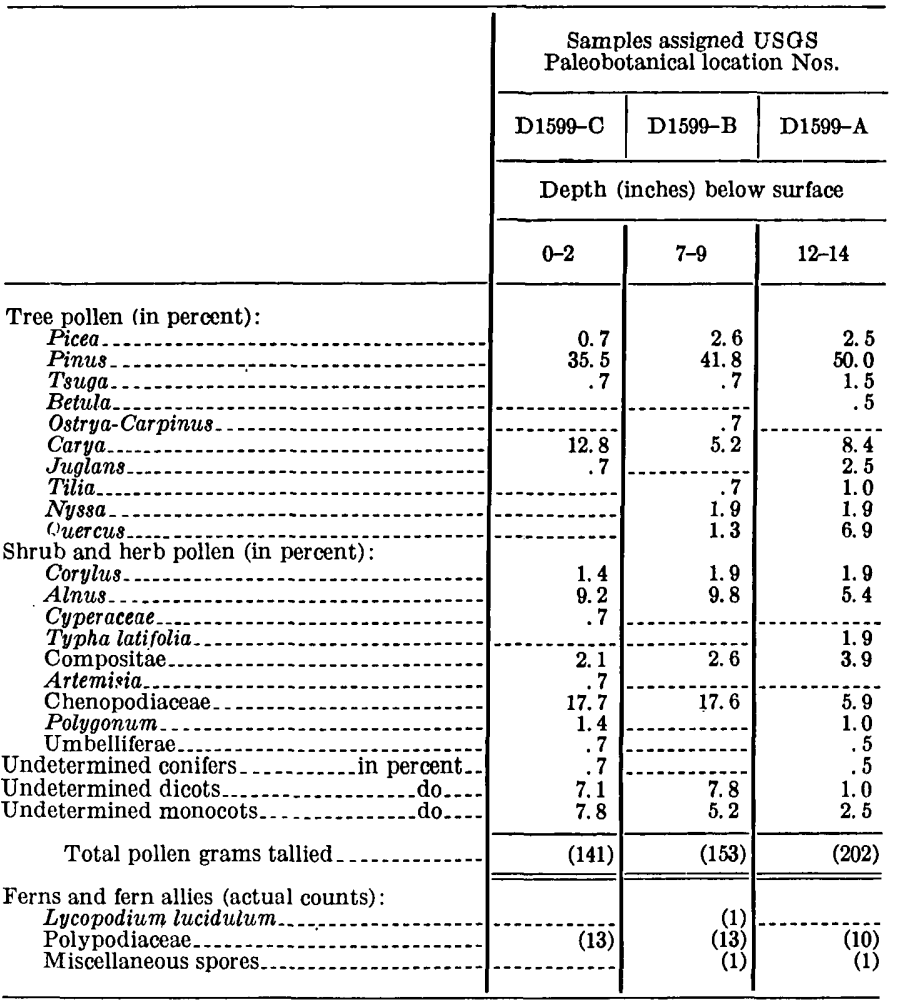

This preliminary study of pollen from a few samples indicates that the marsh has existed for a considerable time, at least 5,000 years. This knowledge is useful in that it implies sufficient time for establishment of a quasi-equilibrium between forces of erosion and deposition in the construction and maintenance of the channel system. 


\section{METHOD OF STUDY}

The principal observational data consisted of the gage height and discharge at selected locations along the length of the estuarine channel. The location of the six measuring sections is shown in figure 3 . This figure shows in detail only one tributary, the one on which section $F$ is located. Recording gages were installed near the upper and lower sections, and at each there was established a semipermanent staff gage. A level survey established the elevations of the staff gages above an arbitrarily chosen datum. At each of the six cross sections, several complete discharge measurements were made by means of a current meter operated from a canoe. Later a continuously recording current meter and, concurrently, a recording water-stage apparatus were installed and operated, first at one section and then at another, over a period of several weeks at each.

A longitudinal profile of the bed extending from section $A$ to the headwater tributary was obtained by sounding and is shown in figure 4. Some samples of bed and bank material for particle-size analysis were collected.

\section{CHANNEL SHAPE AND DRAINAGE NETWORK}

Before embarking on a discussion of the hydraulics of the tidal channels, a description of the drainage network in conjunction with the planimetric maps presented in figures 3 and 5 will provide the reader with some picture of the channels studied. Cross sections up to the level of the marsh - that is, to bankfull stageare presented in figure 6 for each of the six principal measurement locations. In table 3 the principal characteristics of these channel cross sections are compared with river cross sections considered typical for river channels of similar size in the vicinity of Washington, D.C. The table compares width-depth ratios, bankfull discharge, and some other channel parameters.

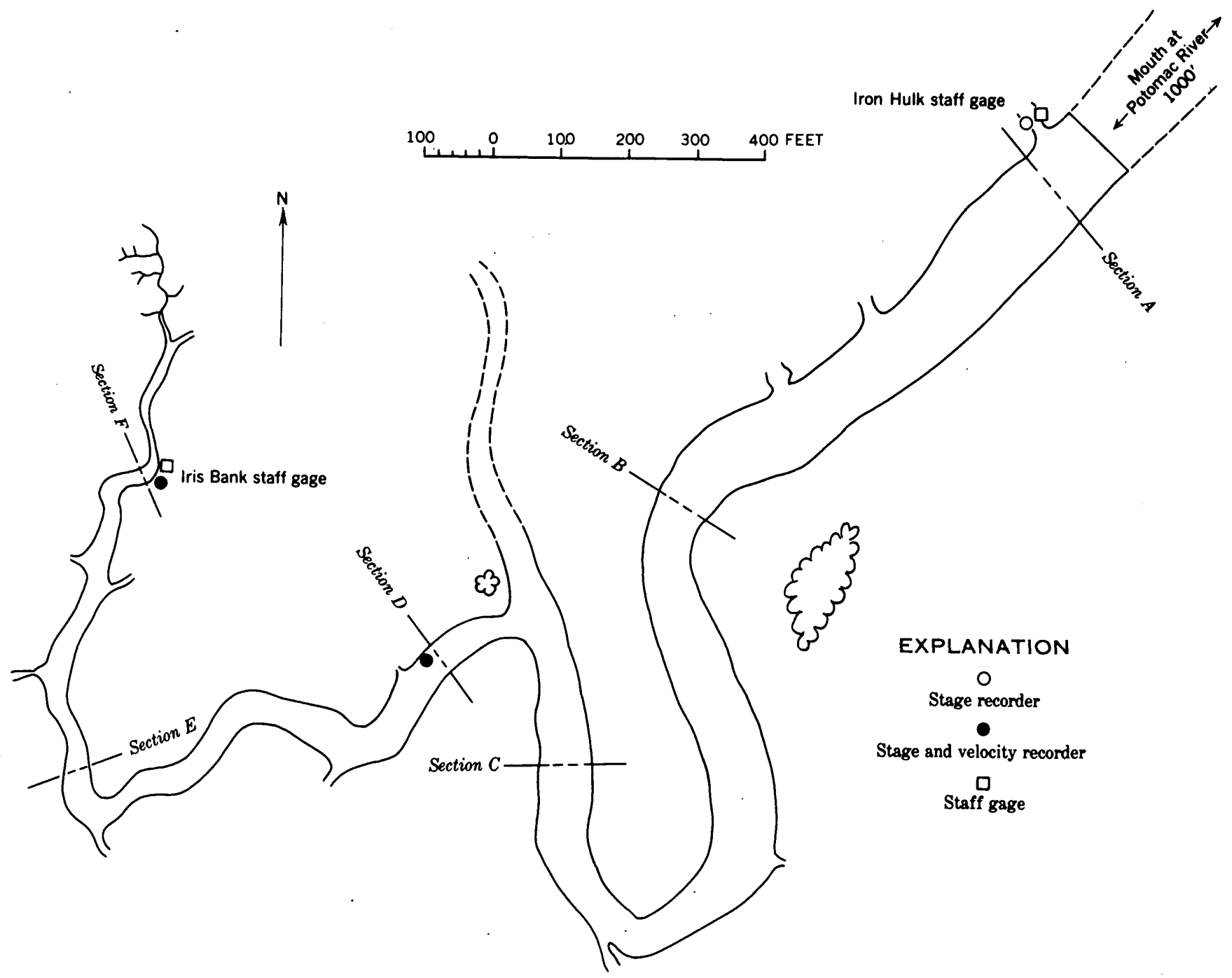

Figdre 3.-Map of Wrecked Recorder Creek at Potomac River, south of Alexandria, Va., showing location of cross sections and recording instruments.

$6751260-63-2$ 


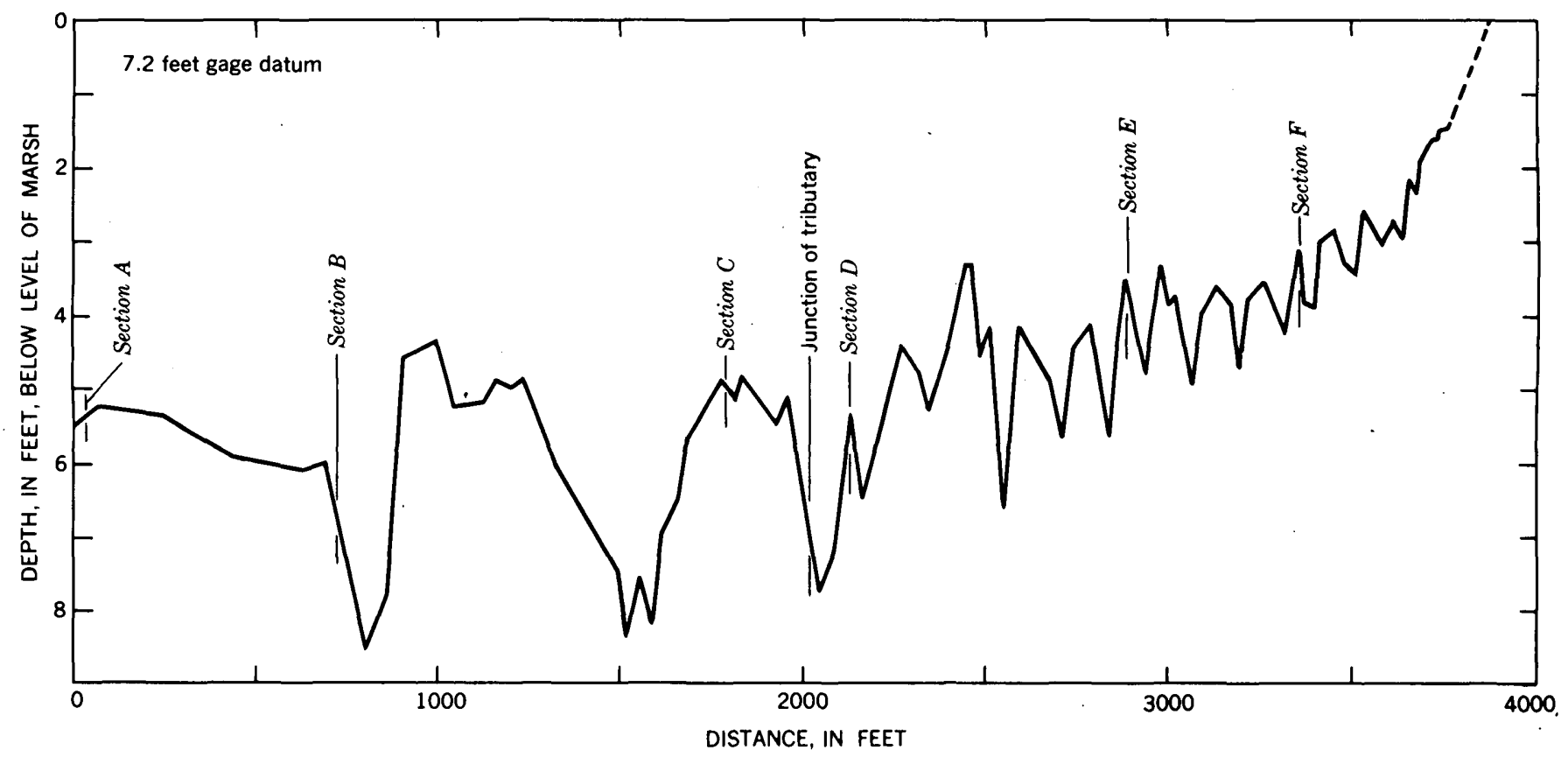

Figure 4.-Longitudinal profile of bed of Wrecked Rècorder Creek; vertical scale is depth in feet below average level of marsh, which is also equal to 7.2 feet on the arbitrary gage datum of the present study.

Table 3 shows that the width of estuarine channels increases with respect to discharge faster than in upland channels. The table does not include enough examples to demonstrate conclusively any generalization about width-depth ratio. Tidal channels are often shallow near the mouth owing to deposition where an estuarine channel joins a large body of water.

TABLE 3.-Characteristics of cross sections of tidal channel and some nearby rivers for comparison

\begin{tabular}{|c|c|c|c|c|}
\hline & $\underset{\text { (ft) }}{\text { Width }}$ & $\begin{array}{c}\text { Depth } \\
\text { (ft) }\end{array}$ & $\begin{array}{l}\text { Width/ } \\
\text { depth }\end{array}$ & $\begin{array}{l}\text { Bankfull } \\
\text { discharge } \\
\text { (cfs) }\end{array}$ \\
\hline $\begin{array}{l}\text { Wrecked Recorder Creek near Alexan- } \\
\text { dria. Va.: } \\
\text { Section } A\end{array}$ & \multirow{7}{*}{$\begin{array}{r}134 \\
82 \\
84 \\
45 \\
32 \\
18 \\
15 \\
86 \\
100 \\
65 \\
38\end{array}$} & \multirow{8}{*}{$\begin{array}{l}4.13 \\
4.77 \\
3.83 \\
3.38 \\
3.00 \\
2.38 \\
3.4 \\
4.2 \\
5.35 \\
3.4 \\
2.0\end{array}$} & \multirow{8}{*}{$\begin{array}{r}32.4 \\
17.2 \\
21.9 \\
13.3 \\
10.7 \\
7.6 \\
4.4 \\
21.6 \\
18.5 \\
19.1 \\
19.0\end{array}$} & \multirow{8}{*}{$\begin{array}{r}1566 \\
1461 \\
1338 \\
1216 \\
1136 \\
147 \\
170 \\
1,320 \\
2,700 \\
1,000 \\
310\end{array}$} \\
\hline$B$ & & & & \\
\hline D. & & & & \\
\hline${ }_{F}^{E}$ & & & & \\
\hline Watts Branch near Rock ville, Md & & & & \\
\hline $\begin{array}{l}\text { Seneca Creek near Dawson ville, Md..- } \\
\text { Rrandvwine }\end{array}$ & & & & \\
\hline & & & & \\
\hline & & & & \\
\hline
\end{tabular}

1 For flood tide having a maximum stage of $8.6 \mathrm{ft}$, and a range in stage of $3.5 \mathrm{ft}$; this one is one combination of range of stage and maximum stage at
during the tidal cycle occurs when the channel is bankfull.

The principal parts of the channel network were mapped by planetable, and the entire headwater network of one small tributary was sketched by pace-andcompass methods. The maps of figures 3 and 5 are sufficient to make a preliminary Horton analysis (Horton, 1945), relating stream order to the number and average length of channels. The smallest channel without a tributary is considered to be of first order and is labeled 1 in figure 5. Channels having only first-order tributaries are labeled 2, meaning that they are of second order. The smallest channel where cross-section and discharge measurements were made is a channel of fourth order (fig. 5). The main channel in the network, on which are located sections $A$ to $C$, is of fifth order.

It is recognized that a map of only one example does not represent the variety of conditions that may occur in the field. Yet it is informative to note the relations of stream order to average length of stream shown in figure 7. As can be seen there, first-order channels average about 20 feet in length, and the fifth-order main channel has a length of 5,000 feet. The length-order relations for the estuary are compared with the same relation for ephemeral streams (Leopold and Miller, 1956, p. 18) and for perennial channels in Pennsylvania (Brush, 1961, p. 156). This estuary increases in length with stream order faster than do either ephemeral or perennial river channels.

The ratio of the number of streams of a given order to the number of the next higher order (called by Horton the bifurcation ratio) ranges for river channel networks from 3 to 4 , often with an average of 3.5. Because only one tributary of the study estuary was mapped in detail, the estimate of the number of streams of various orders is crude. From the limited data for Wrecked Recorder estuary, this ratio averages 3.4 . This 
figure may not be typical of other estuaries, and other similar studies would be informative; yet, as can be seen in figure 8 , this one sample is very similar to two other types of channels in very different environments.
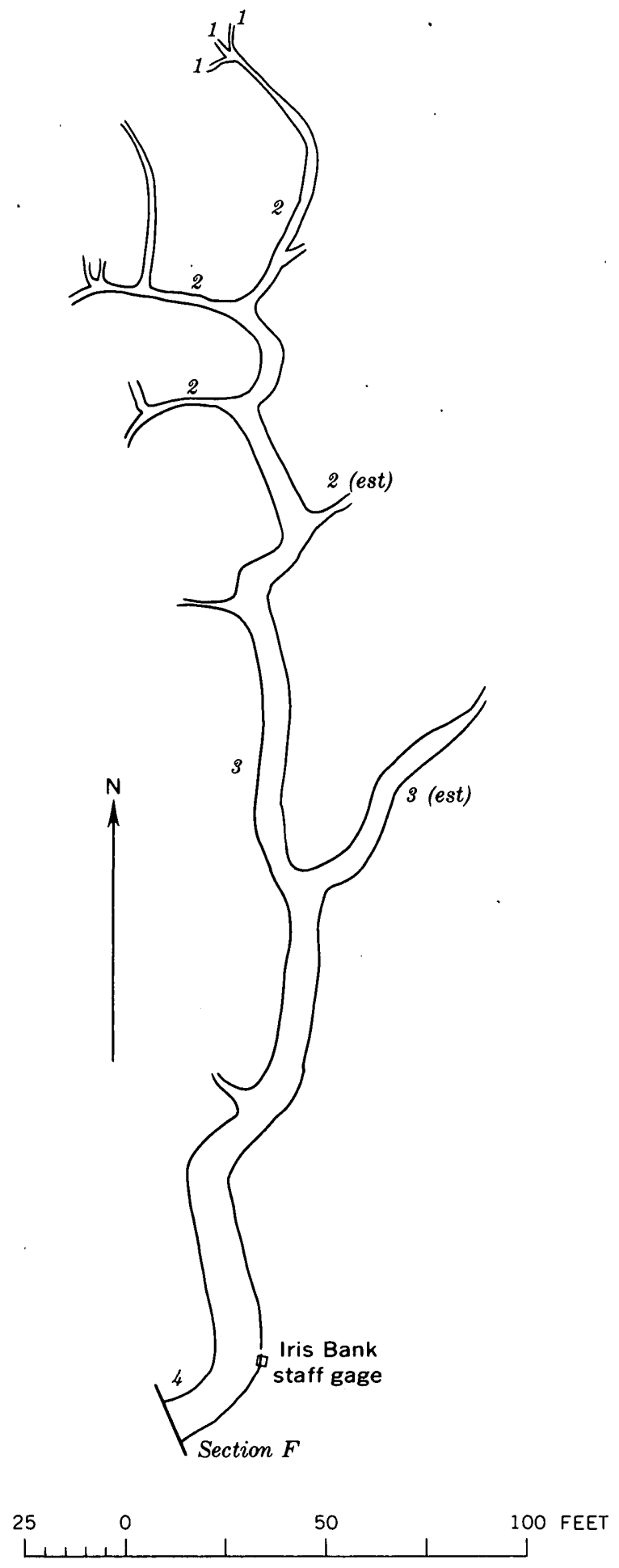

Figure 5.-Detalled map of one tributary of Wrecked Recorder Creek near Alexandria, Va., including all minor channels. Order number of each channel is shown, some of which are estimated (est)

\section{STAGE-DISCHARGE RELATIONS}

The relation of water stage to discharge has been determined for tidal estuaries in many localities, and the characteristic difference between the form of the curve on ebb and flood tide is well known. Nearly all previous observations, however, have been made on relatively large estuaries. With the exception of the studies made by Gilbert (1917, p. 108) in a tidal marsh near San Francisco, no published records are known to us for small tidal channels having no drainage area in the upland. The present investigation adds to Gilbert's work only the comparison of the relations between different cross sections located along the length of the estuarine channel.

Velocity, and thus discharge, at a given stage was dependent both on the maximum stage attained by the particular tidal cycle and on the range of stage in the tidal cycle. Thus, every tidal cycle requires a slightly different stage-discharge curve:

The dependence of velocity on range of tide is known from other investigations. Bradley $(1957$, p. 664$)$, also working in a relatively small estuary, found that the near-bed velocity varied directly with the range of tide. His excellent work does not help solve the particular questions here investigated. All his flow measurements were made close to the estuary bed. Further, he was concerned with a small bay rather than with riverlike estuarine channels.

It was impossible for a party of two to make a complete set of discharge measurements at all sections along the stream simultaneously through a single tidal cycle. We chose, therefore, to make as many discharge measurements as possible through a single cycle at each section, and on different days, making similar measurements on different cross sections. Now the cross-sectional area of each section for any given stage is known from the surveys of the section. The problem is to determine the mean velocity for the whole section at selected stages in order to construct a relation of discharge to stage. For two tidal cycles the relation of velocity to stage is shown in figure 9 , using section $D$ as an example. Such graphs alone, however, do not give sufficient information to determine the influence of either tidal range or maximum stage.

To incorporate these additional variables, two sections were chosen for a more intensive series of velocity measurements covering different tidal cycles. At sections $D$ and $F$ a recording current meter was installed, along with a device that recorded water stage simultaneously. Thus, at a particular distance above the bottom, velocity was measured near the center of the channel continuously for two weeks to sample tidal cycles from spring to neap tides. 

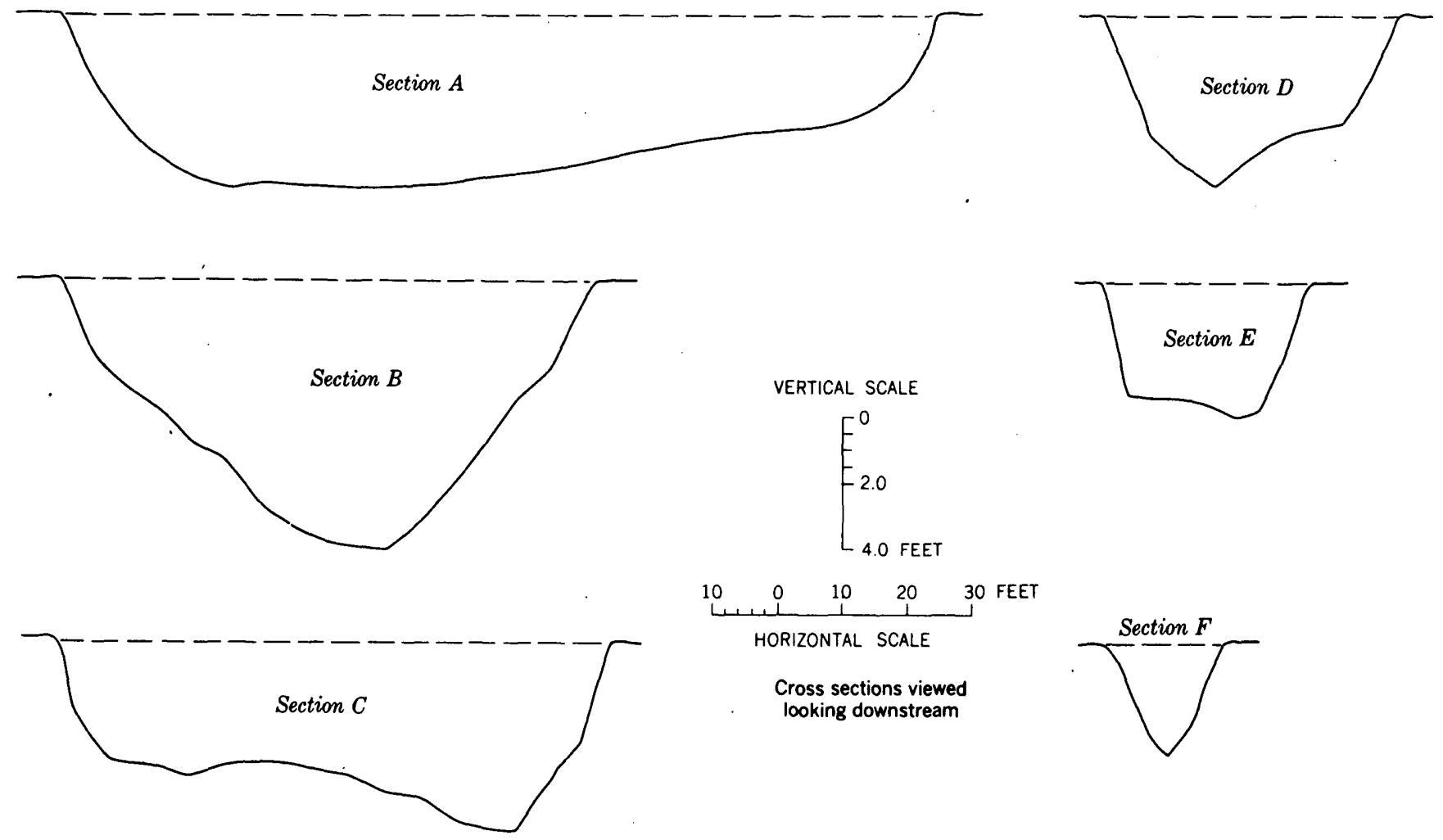

Froura 6.-Cross sections viewed looking downstream of each of the principal measuring places along the channel of Wrecked Recorder Creek. Vertical scale is feet below average level of marsh.

The location and depth of the recording current meter were selected on the basis of velocity readings from previous measurements to provide a position where point velocity best correlated with mean velocity. Owing to the variation in water depth throughout the tidal cycle, the depth below the water surface where the meter was installed changed. The position of the recording meter varied from three-tenths to seventenths of the full depth below water surface at section $D$, and from two-tenths to eight-tenths at section $F$. The velocities recorded at the single point during a given cycle correlated reasonably well with measured mean velocities for the whole section. From this correlation, the relation of mean velocity to stage and to range of stage could be constructed.

For each cross section, curves of the type shown in figure 10 were developed to show the stage-velocity relation for each of several values of range in stage. The curves shown by full lines in figure 10 are merely selected examples which comprise three values of maxi- mum stage, each with a different range in stage. For one of these examples, an additional graph is shown (dashed line) representing the condition of another value of range in stage but identical maximum stage. It will be visualized that there may be a very large number of curves making up such a family as that shown in figure 10.

The graphs drawn in the interpolation procedure are considered reasonably reliable except for very low velocities, but even there the error in velocity does not exceed 10 percent. Minor variations in individual cycles were neglected in the construction of the graphs.

Most data in tidal studies have been presented as graphs of stage or velocity as a function of time in a tidal cycle (for example, Gilbert, 1917, p. 124; Ahnert, 1960 , p. 397). Our data plotted in that usual way exhibit the usual features (fig. 11). Minor variations occur in individual tidal cycles; velocity decreases toward zero with time in a somewhat irregular manner in the early part of the ebb tide. 


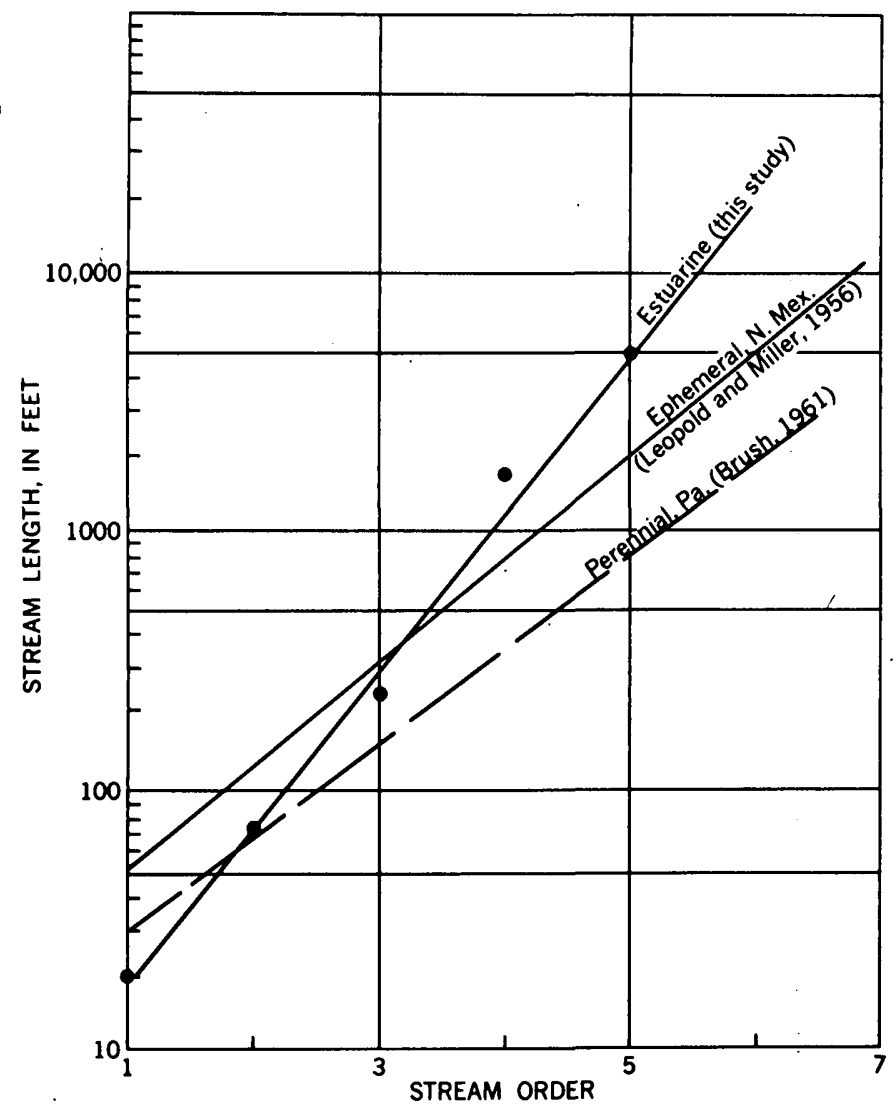

Fropg 7-Relation of stream length to stream order for Wrecked Recorder Creek and for some other drainage areas. The data from Brush (1961) were extended to account for differences in map scale, and his order 1 was comparable to order 5 in the present study. Dots represent measurement data frop this study.

\section{BANKFULL DISCHARGE}

The evaluation of the banks relative to gage datum was determined by visual observations at several sections in the reach during the flood tides. The stage at which the flow started to inundate the marsh ranged from 7.1 to 7.3 feet, and averaged 7.2 feet (relative to our arbitrary datum) for the reach. The difference between the elevation of the marsh at the headwaters and at the mouth is very small.

In upland river systems, the higher the discharge the less frequently it is experienced. Except for very low flows, this inverse relation of discharge rate and frequency of occurrence is a general characteristic of rivers.

In tidal channels, on the other hand, zero discharge occurs twice in every tidal cycle, and thus there are also two occurrences of high discharge in each cycle. There remain different frequencies of the different values of the peak discharge from cycle to cycle, but the range of values possible is much smaller than the range of possible values of flood flows in an upland river of the same size.

Because of this difference, it may be fruitful to examine the frequency of occurrence of the factors which do vary.

Figure 12 shows the percentage of time the high and low tides equal or exceed a given stage at the Alexandria, Va., tide gage. The ordinate shows the variation in terms' of the datum uesd in Wrecked Recorder Creek.

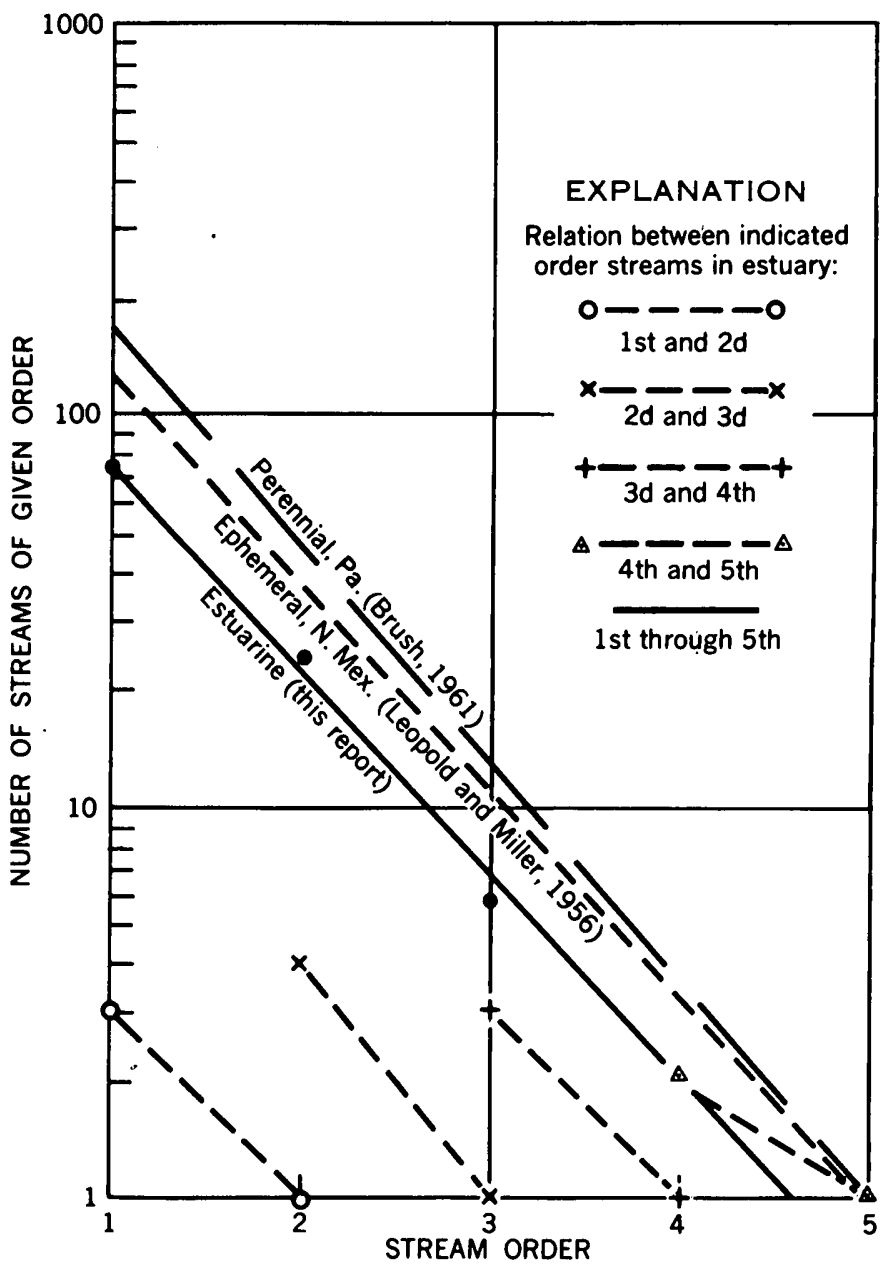

Figure 8.-Relation of number of streams to stream order; data for Wrecked Recorder Creek are compared with average relations for an area of perennial streams and an area of ephemeral streams. 


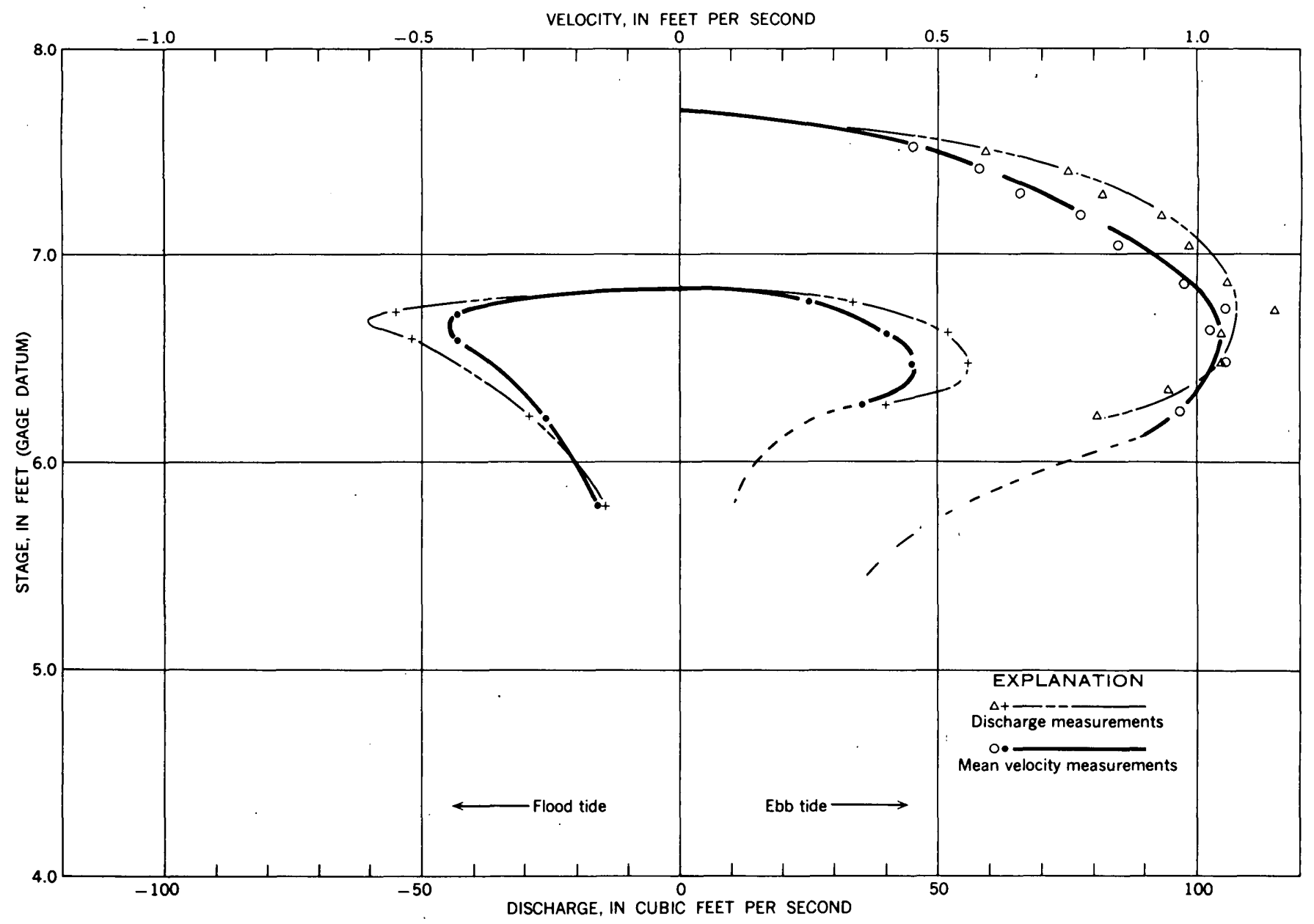

Figdre 9.-Stage-discharge relation (light line) and st: ge-velocity relation (heavy line); a nearly complete tidal cycle having a maximum stage of 6.8 feet is shown and the ebbing limb only is shown for a tidal cycle in which maximum stage was 7.6 feet. Data are for section $D$. The velocity shown is mean velocity in the cross section.

A comparison of our observations with the concurrent values of stage of the Potomac estuary at Alexandria showed that the stage at the two locations varies in a comparable manner, and this indicates that the frequency of stage at the two locations is comparable. To eliminate the effect of the spring and neap tides, a period of 2 lunar months, 58 days, was used in the preparation of the frequency data. The extremes shown by dashed lines were extended on the basis of a straight-line projection.

From the graph we find the median high tide for this area is 7.27 feet relative to our local datum. Bankfull stage, 7.2 feet, is, interestingly, approximately the median high tide and is therefore attained on the average every other tidal cycle or once a day. A terrestrial river reaches its bankfull stage but once every 1 or 2 years.
This, though true, leaves an incomplete and perhaps false impression in the mind of the student of channel morphology. We are interested, after all, in the frequency of the effective discharge.

In an estuarine channel, at some value of stage near high tide, velocity must be zero, for the direction of flow must reverse. In Wrecked Recorder Creek, the velocity is highest at a stage much lower than high tide.

The velocity and the stage corresponding to maximum discharge both increase with the maximum stage of of any given tidal cycle. The stage at which the maximum velocity occurs is not well defined by the available data; but as a rough approximation, a tide reaching a maximum stage of 8 to $81 / 2$ feet is required for the maximum velocity to occur at a stage of 7.2 feet, which is the bankfull stage. Thus, because of the dependence of dis- 


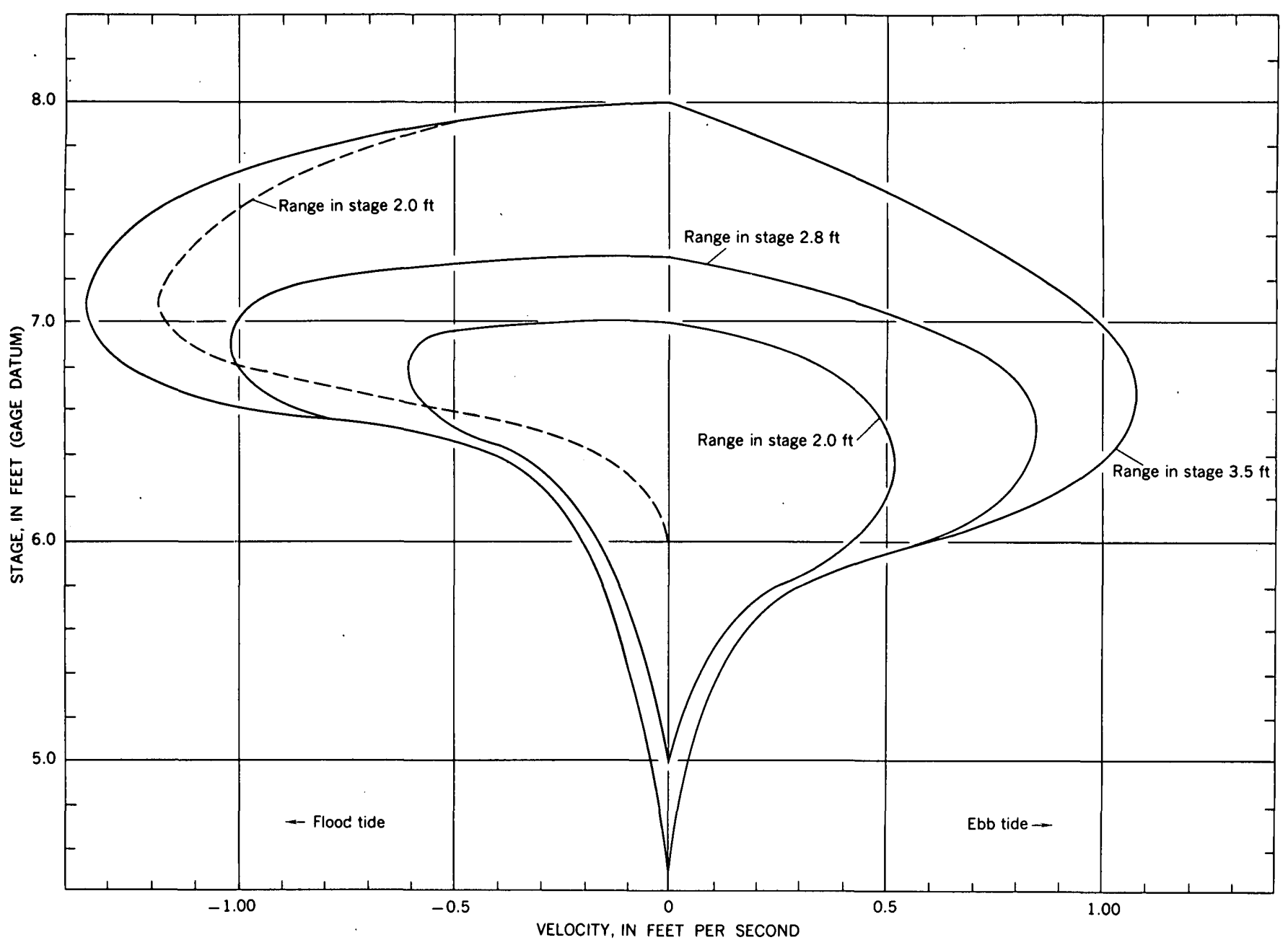

Figure 10.-Sample relations of stage to velocity at section $D$ showing effects of maximum stage and of range in stage. The samples include varlous maximum stages, $7.0,7.3,8.0$ feet. Two samples are for the same maximum stage ( 8.0 feet) but illustrate different ranges of stage, 3.5 feet and 2.0 feet, respectively.

charge on velocity at a given stage, the top of banks is also the level of maximum discharge when the high tide occurs at the stage between 8 and $81 / 2$ feet.

From an analysis of records of the Alexandria tide gage, a high tide of 8.5 feet is equaled or exceeded about 0.9 percent of the time, and 8.0 feet about 9 percent of the time. Nixon (1959) found that bankfull stage is equaled or exceeded 0.6 percent of the time in English rivers. These results are of the same order of magnitude. Whether this is coincidental or morphologically important cannot be stated in the present state of knowledge. It is a problem worth further work. It is hoped that further investigations on estuarine streams will consider the problem of the dominant discharge.

\section{HYDRAULIC CHARACTERISTICS AT A CROSS SECTION}

In terrestrial rivers, changes in width, depth, and velocity at any cross section accompany a change in discharge. These variables are related to discharge as simple power functions expressed by Leopold and Maddock (1953) in the following form:

$$
\begin{gathered}
u=a Q^{b} \\
d=c Q^{f} \\
v=k Q^{m}
\end{gathered}
$$

where $Q$ is discharge, $v, d$, and $v$ represent the watersurface width, mean depth, and mean velocity, respectively. The coefficients, $a, c$, and $k$, are constants, and $b, f$, and $m$ are exponents representative of the section. 


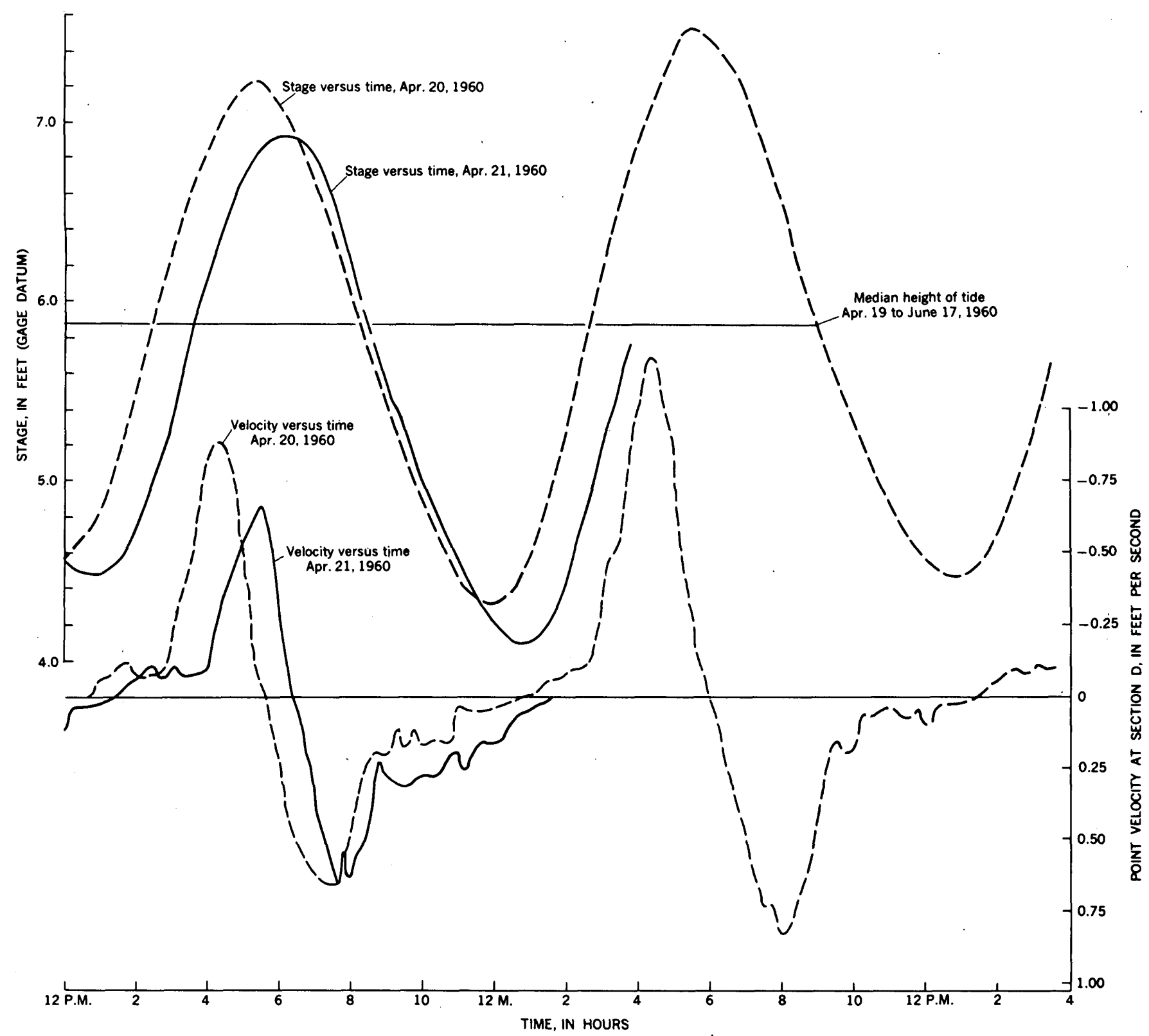

Figure 11.-Stage and velocity as functions of time at section $D$. High tide during the three cycles shown was below, at, and above bankfull stage, 7.2 feet.

Hydraulic geometry is a phrase coined to express these and collateral equations at-a-station and in a downstream direction. In the present study, similar curves were constructed for a tidal estuary.

It has been previously stated in the discussion of the velocity-stage curve that an unlimited number of velocities are possible at any stage for a given cross section. The effect on at-a-station curves of range in stage and of high tide at one station or section is not large compared with differences between channels in different areas. Figure 13 presents data for three flood tides in the study area. The figure also includes data from Gilbert's study (1917) and some data collected by- the authors in Old Mill Creek, Del.

For Wrecked Recorder Creek, figure 13 shows the changes in width, depth, and mean velocity as functions of discharge in flood tide only at section $D$. Other sections would have similar curves, and the ebbing limb of a tide would differ principally in the direction of the hysteresis loop. 


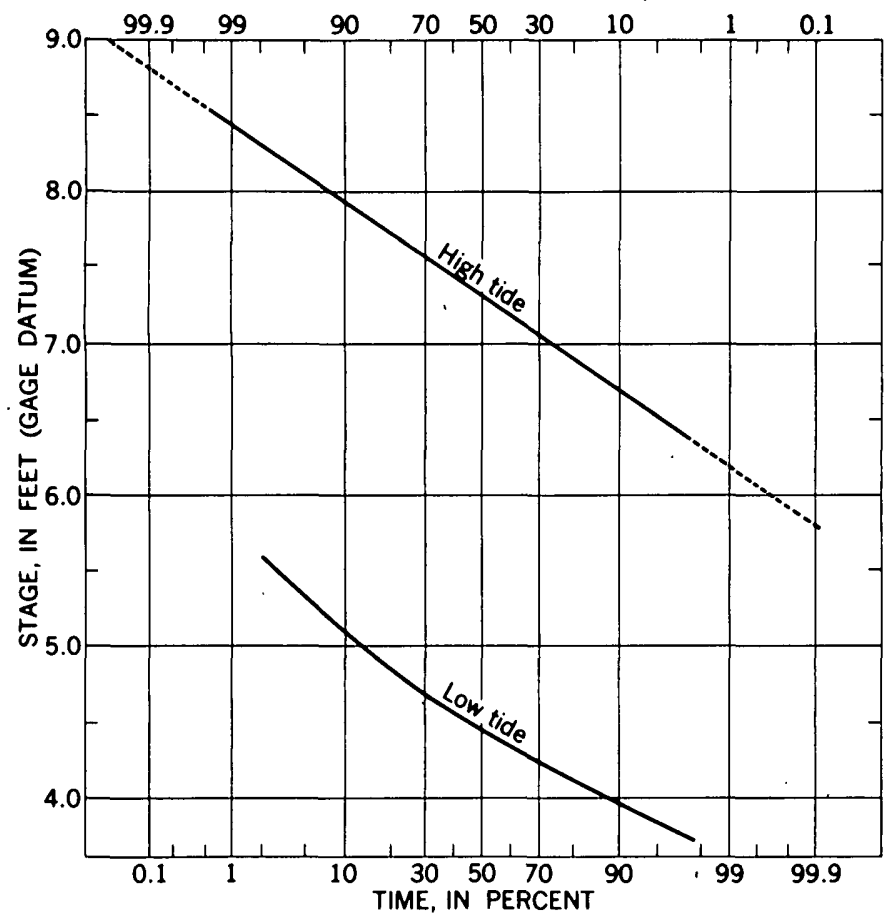

Fiaurv 12-Duration curves (cumulative frequency) of values of stage at high and low tide, Alexandria, Va., tide gage. Datum is the arbitrary datum used at Wrecked Recorder Creek.

Figure 13, thus presents for Wrecked Recorder Creek two sets of curves; each set represents a different tidal cycle and is indicated separately by crosses and triangles. The results of three current-meter measurements, represented by dots, are shown for comparison. Widths for stages above 7.2 feet (bankfull) were determined by a straight-line extension of a width-stage curve, and discharges were based on these widths. The set of curves indicated by a dashed line represent a flow below bankfull stage during the complete tidal cycle.

The two tides give such similar results that the slopes for each set of curves are nearly identical. Each tidal cycle will give a separate set of curves, but the slopes are consistent.

It can be visualized that in a flood limb of a tidal cycle, width and depth increase progressively from zero discharge through maximum to zero discharge. Velocity, on the other hand, begins with zero, reaches a maximum value at or near the stage of maximum discharge, and decreases to zero at the highest value of depth when flow reverses. Because figure 13 presents a flood tide only, the arrows show only one direction of progression around the hysteresis loop.

The respective slopes of the lines representing relations of width, depth, and velocity to discharge were nearly identical on flood and ebb limbs of a tide. Thus, it is possible to discuss the relation of these slopes as exponents in power function equations, and to compare the exponents with those applicable to terrestrial rivers.

For Wrecked Recorder Creek, values at given cross sections during flood tide of the exponent constants, $b, f$, and $m$, are:

\begin{tabular}{|c|c|}
\hline Increasing velocity & Decreasing velocity \\
\hline vidth. & -0.01 \\
\hline Change in depth.---------.. & $f=-.04$ \\
\hline Change in velocity & $m=1.05$ \\
\hline
\end{tabular}

For an upland stream from Leopold and Maddock $(1953$, p. 26$)$ the average values are:

$$
\begin{array}{r}
b=0.26 \\
f=.40 \\
m=.34
\end{array}
$$

In the values for the tidal channel, the left-hand column is undoubtedly the more important from the standpoint of channel morphology. The increasing velocity is related to flow in the channel, whereas when the velocity decreases on a flood tide at least part of the discharge is usually governed by conditions of overflow rather than channel hydraulics.

The small value for the exponent $b$ in the estuarine channel was expected because of the relatively vertical banks prominent throughout the reach except at the bends.

The median range in tide in the vicinity of the project area is 2.8 feet, although under extreme conditions a range of more than 4 feet may be expected. Increasing velocity occurs principally in the lower segment of the range in stage. As an example, on a high tide of 8.6 feet with a range in stage of 3.6 feet the maximum velocity occurs at a stage of 7.2 feet or 1.4 feet below the maximum stage.

It is not known whether the value for the exponent $f$ for Wrecked Recorder Creek is also representative of the numerous areas where a large range in stage occurs during each tidal cycle. Some data are available for comparison as discussed below, but more examples are needed.

Old Mill Creek differed from Wrecked Recorder Creek by being longer and deeper. The former also drains some area of upland whereas the latter does not.

Gilbert (1917, pl. 33) presented a graph which included the velocity, discharge, and stage for Ravenswood Slough on the southwest shore of San Francisco Bay. The range in stage for one of the flood tides illustrated was over 7 feet. From his published data, width at any given stage could be measured, and depth 

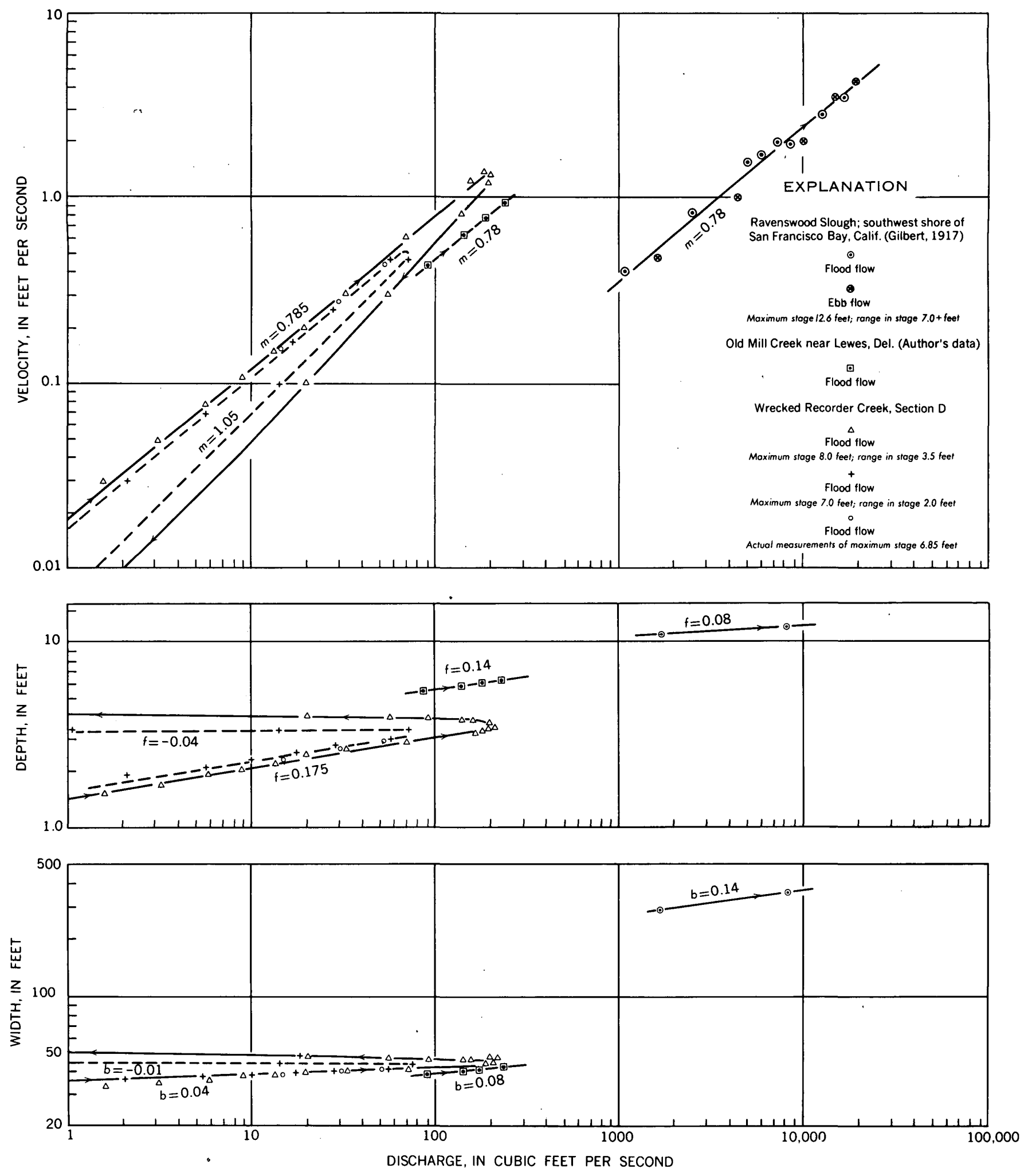

FIGURE 13.-Changes at-a-station of width, depth, aud velocity as functions of discharge. Data for Wrecked Recorder Creek were collected at section $D$. Also included are observations at Old Mill Creek estuary, near Lewes, Del., and Ravenswood Slough, San Francisco Bay, Calif. 
versus discharge computed from the width and velocity. The error in reading values of velocity, width, and discharge from his data is less than 10 percent.

The three examples presented in this report are only a small sample of the numerous variations in tidal channels. Because of the vast difference in the three channels, it is surprising that the values of the exponents in the equations are as comparable as they are.

The following tabulation summarizes the observed values of exponents in the equations for width, depth, and velocity, respectively, relative to discharge at a cross section, and on the rising velocity of a flood tide.

\begin{tabular}{|c|c|c|c|}
\hline \multirow{3}{*}{. } & \multicolumn{3}{|c|}{ Change of- } \\
\hline & width & depth & velocity \\
\hline & 0 & $f$ & $m$ \\
\hline $\begin{array}{l}\text { Sec. } D \text {, Wrecked Recorder Creek } \\
\text { Old Mill Creek } \\
\text { Ravenswood Slough. }\end{array}$ & $\begin{array}{r}0.04 \\
.08 \\
.14 \\
\end{array}$ & $\begin{array}{r}0.18 \\
.14 \\
.08\end{array}$ & $\begin{array}{r}0.78 \\
.78 \\
.78\end{array}$ \\
\hline $\begin{array}{l}\text { Average } \\
\text { Average for terrestrial rivers. }\end{array}$ & $\begin{array}{l}.09 \\
.26\end{array}$ & $\begin{array}{l}.13 \\
.40\end{array}$ & $\begin{array}{l}.78 \\
.34\end{array}$ \\
\hline
\end{tabular}

As can be seen in figure 13, the curves for width and depth versus discharge have slightly negative slopes as discharge decreases from its maximum value to zero at high tide. Thus the values of the exponents $b$ and $f$ given above would be smaller rather than larger if averaged with those applicable to decreasing discharge on the floodtide. It must be concluded then that the principal difference in the at-a-station hydraulic characteristics of estuarine and terrestrial streams is that the former have a much more rapidly changing velocity with discharge than do terrestrial rivers. This is compensated by less rapidly changing depth and width with discharge.

\section{THEORETICAL ANALYSIS OF THE HYDRAULIC GEOM- ETRY IN THE DOWNSTREAM DIRECTION}

By Walter B. Langbein

Pillsbury (1939, p. 228-230) defined an ideal estuary as one in which the tidal range, depth, and current are uniform through the length of the channel. By analysis of the motion of water in the channel as induced by the tides at the mouth and as retarded by friction, Pillsbury showed that in such an estuary the width decreases exponentially with the distance up the estuary; thus

$$
v=w_{0} e^{-n x \cot \varphi}
$$

where $w=$ width at distance $x$ upstream from the mouth where width is $v_{n}, e$ is base for natural logarithms, $\varphi$ is the lag (in degrees) between the time of maximum slope and the time of maximum velocity, and $n$ is the quantity $a / \sqrt{g D}$ where $a$ is the mean angular speed of the semidiurnal lunar tide $=0.00014$ radians per second, $D$ is mean depth at a given cross section, and $g$ is the acceleration of gravity. This equation describes an estuary decreasing in width exponentially with distance.

Pillsbury showed that tidal estuaries tend to approximate this exponential form, generally with a sinuous alinement. The analysis is based on an assumption of a single channel estuary. Presumably, if applied to a branched estuary the width, $w$, must be the total width at distance $x$. There is, however, a well known tendency for natural channels to become shallower as they become narrower. It will be instructive to deduce the hydraulic geometry of an estuary in the terms defined by Leopold and Maddock (1953), and to introduce concurrently some of the principles of hydraulic probability described by Leopold and Langbein (1962). That report treats the distribution of energy in natural sys. tems, in which known physical relations or constraints are insufficient to yield unique solutions-in other words, a system with remaining degrees of freedom. From analogy to entropy production in thermodynamics, it was shown that a river system, in adjusting to the remaining degrees of freedom, would tend toward uniform distribution of energy, and a minimum rate of work in the system as a whole. Pillsbury, for example in postulating equal depth and velocity in an estuary introduced only the first of these conditions. This is incomplete. We shall explore the effect of minimizing total work as well.

The amount of work done by the tide in filling and emptying the estuary is a function of the volume of the tidal prism and of the hydraulic friction. Both these quantities are related to the width and depth of the estuary.

If change in depth is described by the function $D=D_{o} e^{-k x}$ where $D_{o}$ is mean depth at the mouth of the estuary, an approximate equation describing the width of an estuary is as follows:

$$
w=w_{0} e^{-(n \cot \varphi+k) x}
$$

According to this equation, the estuary will narrow and thus the tidal prism lessen more rapidly, the greater the rate of decrease in depth. Other hydraulic relations that govern flow in an estuary are as follows:

Continuity.-Since $Q=v d w$ at each cross section, the relation $m+f+b=1.0$ must be satisfied.

Slope-depth relation.-Slope in this case is the surface slope of the water surface created by the progress of the tide in the estuary. The slope varies sinusoidally during the tidal cycle. As Pillsbury shows, the value of $s$ (amplitude of the slope) is a function only of the depth, thus:

$$
s=A a / \sqrt{g D}
$$

where $A$ is the tidal amplitude (half the range be- 
tween mean high water and mean low water), and $a$ and $D$ are as described previously.

The average value during one phase of the tidal cycle will be $0.63 S$ and

$$
\bar{S}=0.63 A a / \sqrt{g \bar{D}}
$$

Since

$$
S \propto D^{-\frac{1}{2}}
$$

Hence

$$
Q^{z} \propto Q^{-f / 2}
$$

$z=-\frac{1}{2} f$

Velocity-depth relation.-The amplitude of the tidal current is as follows:

$$
V=A \sqrt{g / D} \sin \phi
$$

where $\phi$ is the angular lag of the primary current behind the hydraulic slope. The value of $\phi$ is itself a function of depth and channel friction, and is evaluated by tables given by Pillsbury (1939, p. 123). Using a Chezy coefficient of 80 and mean depth of cross sections ranging from 2 to 10 feet, the value of the amplitude of the current is calculated to be

$$
V=0.35 A D^{1 / 5}
$$

Velocities during the tidal cycle will vary sinusoidally in proportion to the amplitude $V$. Mean velocities at different cross sections vary as the fifth root of the mean depths, therefore, $m=f / 5$.

Thus we have the three following hydraulic conditions :

$$
\begin{aligned}
m+f+b & =1.0 \\
m & =f / 5 \\
z & =-f / 2
\end{aligned}
$$

There are four unknowns; the remaining statement will be supplied by the necessity that the estuary approach a state in which energy is as uniformly distributed as is consistent with the necessity that total work in the estuary as a whole be a minimum.

The first condition is satisfied if velocity and depth are uniform; hence, $m+f$ must approach zero. Since $m$ and $f$ are of the same sign, each of the parameters, $m$ and $f$, also would approach zero. Since $m+f+b=1.0$, $(1-b)$ approaches zero.

The second condition, that of minimum total work, is met as the integral $\sum_{0}^{\infty} Q s d x$ approaches zero. In the upland river, $Q$, the discharge, is the land drainage and is independent of the channel geometry, and slope is the only variable. The discharge in an estuary, however, is uniquely a function of its size and thus of its width, depth, and length, and so the problem is more complex.
The relative work performed during a tidal cycle in an estuary is as follows:

$$
P=\frac{n \cot \varphi}{1.7+n \cot \varphi}
$$

where $P$ is the ratio of the integral $\sum_{0}^{\infty} Q s d x$ for an estuary in which the depth varies as $D_{o} e^{-k x}$, to the same integral for an estuary in which the depth does not vary, that is, $k=0$.

This equation shows that the relative work decreases as the depths decrease upstream from the mouth. As was shown previously, the decrease in depth affects the estuary width, and so affects the value of the exponent $b$ in the relation between width and discharge, $v \propto Q^{b}$, where $w$ is the channel width at a given cross section and $Q$ is the bankfull discharge. For an estuary in which depth does not decrease, the value of $b$ is unity. For an estuary in which depths decrease upstream from the mouth, the value of $b$ decreases. The relation is as follows:

$$
b=\frac{k+n \cot \varphi}{2.2 k+n \cot \varphi}
$$

Formulas 1 and 2 can be solved to determine the relation between the relative work $P$ and the width exponent $b$, thus :

$$
P=\frac{1.3 b-0.59}{0.3 b+0.41} \text { or as a more convenient }
$$

approximation :

$$
P=1.7 b-0.7
$$

As stated previously, the condition of uniform energy distribution requires $(1-b)$ to approach zero. Thus $b$ should be high. On the other hand, minimum work requires $1.7 b-0.7$ to approach zero-in other words, $b$ should be low. Following the logic developed in the paper by Leopold and Langbein (1962), the most probable value of $b$ is that for which the probability of the deviation of $(1-b)$ from $b$ equals the probability of a deviation of $1.7 b-0.7$ from $b$. These two probabilities are equal when

$$
\frac{F_{1}(b)}{\sigma F_{1}}=\frac{F_{2}(b)}{\sigma F_{2}}
$$

where $F_{1}(b)=1.7 b-0.7$ and $F_{2}(b)=(1-b) . \quad \sigma F_{1}$ and $\sigma F_{2}$ are the standard deviations of those quantities. The absolute values of the standard deviations need not be known. Each can be expressed in terms of the standard deviation of $b$, thus

$$
\begin{gathered}
\sigma F_{1}=1.7 \sigma b \text { and } \\
\sigma F_{2}=\sigma b
\end{gathered}
$$


Hence

$$
\frac{1.7 b-0.7}{1.7 \sigma b}=\frac{1-b}{\sigma b}
$$

or $b=0.71$, which leads to the following set of values of the hydraulic geometry exponents:

$$
\begin{aligned}
m & =0.05 \\
f & =.24 \\
b & =.71 \\
z & =-.12
\end{aligned}
$$

These results derived without reference to field measurements will be compared in the next section with data obtained in the tidal creek studied.

\section{MEASUREMENTS OF THE HYDRAULIC GEOMETRY IN THE DOWNSTREAM DIRECTION}

In the discussion of channel characteristics, the changes in width, depth, and velocity in the downstream direction are also important. A representative discharge for all cross sections is required for this analysis. The dominant or bankfull discharge is probably the most meaningful for terrestrial rivers. The estuarine channel presents the problem of what value of discharge is pertinent. It is reasonable to assume that the discharge occurring at the time of maximum velocity at a section is a pertinent discharge. This occurs nearly simultaneously at all sections in a channel as short as Wrecked Recorder Creek because the time lag along the length of the channel is small. It is this discharge that is used in the computation of the downstream curves in figure 14.

The data used in construction of the curves represent flood and ebb flow during a tidal cycle having a high tide of 8.6 feet, for which some measurements are summarized for floodtide in table 3 .

From the slopes of the lines in figure 14 the values of the exponents in the hydraulic geometry may be

\begin{tabular}{|c|c|c|c|c|}
\hline & \multirow[b]{2}{*}{$\begin{array}{l}\text { Theoretical } \\
\text { (Langbein) }\end{array}$} & \multicolumn{2}{|c|}{ Tidal estuaries } & \multirow{2}{*}{ 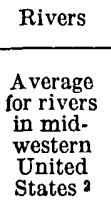 } \\
\hline . & & $\begin{array}{l}\text { Wrecked } \\
\text { Recorder } \\
\text { Creek } \\
\text { (this } \\
\text { report) }\end{array}$ & $\begin{array}{c}\text { Barnstable } \\
\text { Marsh, } \\
\text { Mass. }\end{array}$ & \\
\hline $\begin{array}{l}\text { Exponent of width, } b \\
\text { Exponent of depth, } f_{-} \\
\text {Exponent of velocity, } \\
\text { Exponent of slope. }\end{array}$ & $\begin{array}{r}0.71 \\
.24 \\
.05 \\
-.12\end{array}$ & $\begin{array}{r}0.77 \\
.23 \\
.00\end{array}$ & $\begin{array}{r}0.74 \\
.17 \\
.09 \\
- \\
\end{array}$ & $\begin{array}{r}0.50 \\
.40 \\
-.10 \\
-.49\end{array}$ \\
\hline
\end{tabular}
determined. The curves represent the average of both flood and ebb flows.

Values of exponents in the hydraulic geometry, with respect to increasing discharge downstream

1 Preliminary estimates by Alfred C. Redfield and Lincoln Hollister communicated

by letter to Leopold, Mar. 30, 1962 .
Langbein's theoretically derived values of these exponents are compared below with the values determined from the present field investigation of Wrecked Recorder tidal stream. Also included are values from field data collected and analyzed by Redfield and Hollister at Barnstable Marsh, Mass.
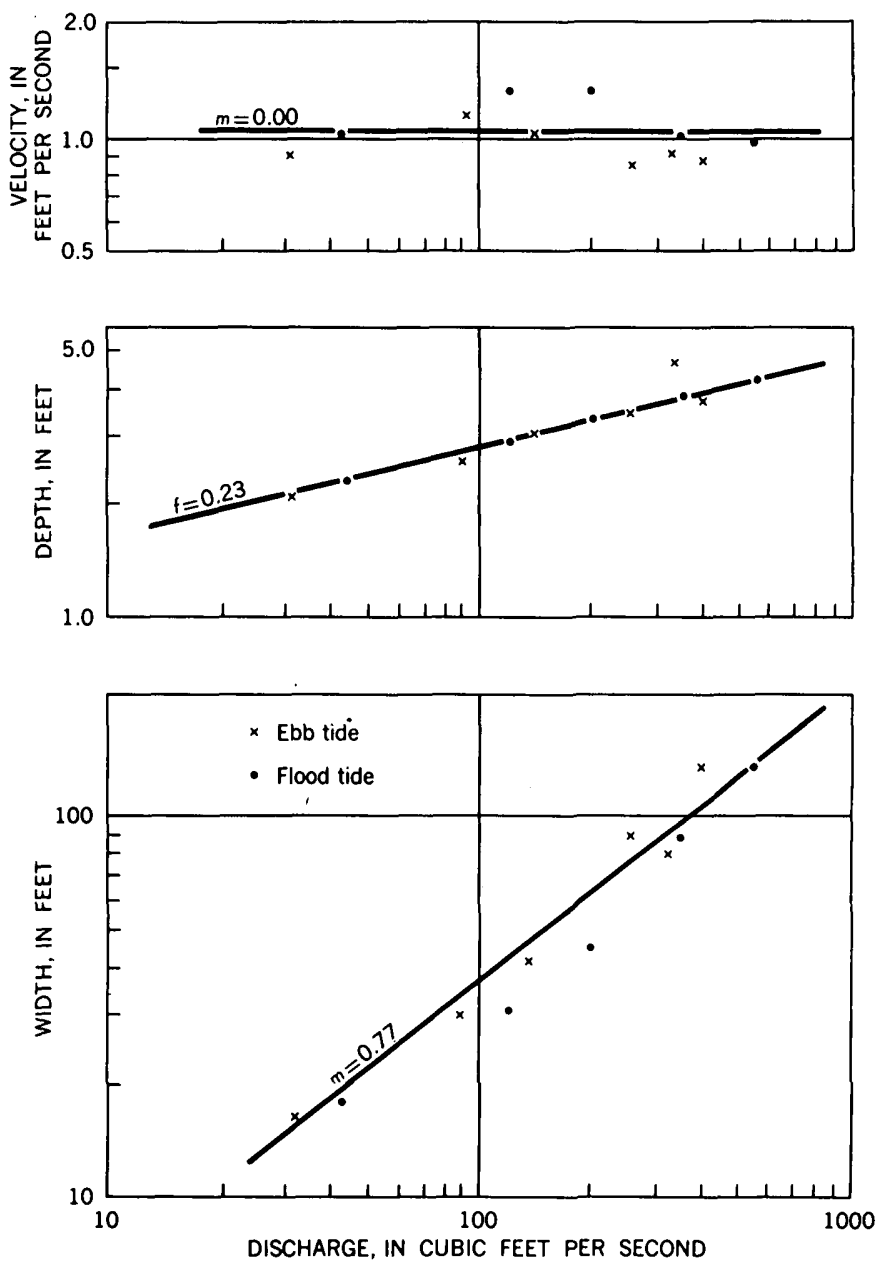

Figdre 14.-Downstream or along-the-channel changes in width, depth, and velocity as functions of discharge, at bankfull stage in Wrecked Recorder Creek.

The data from Redfield and Hollister are particularly valuable because the channel studied ranged in width from 10 feet near the headwaters to 3,800 feet near the mouth. This is a much greater range in channel size than in our study and yet there is remarkable agreement of the results.

The agreement between the field results of this investigation and the theory is very: satisfactory. The field data, however, are few and the scatter is large. More field data are needed.

Both theory and field data show that in tidal estuaries, depth tends to be more conservative (a low value of $f$ ) 
than in upland rivers, so that the width-depth ratio varies rapidly downstream. At the mouth, a tidal estuary is wide and relatively shallow; at its head, it is narrow and relatively deep. The reason for this is that, in contrast to rivers, the discharge at any section is itself a dependent variable depending on how the flow shaped the channel in all the channel length between the point in question and the main bay or body of tidal water. In a terrestrial river, discharge is independent in that it is produced by the watershed and the channel is accommodated to it, rather than by such accommodation modifying the discharge itself.

It is this influence of the channel on discharge that makes the rates of change of width, depth, and velocity along the channel different than in terrestrial rivers.

\section{REFERENCES}

Ahnert, Frank, 1960, Estuarine meanders in the Chesapeake Bay area : Geog. Rev., v. 50, no. 3, p. 390-401.

Bradley, W. H., 1957, Physical and ecologic features of the Sagadahoc Bay Tidal Flat, Georgetown, Maine: Geol. Soc. America, Mem. 67, p. 641-682.

Brush, L. M., Jr., 1961, Drainage basins, channels, and flow characteristics of selected streams in central Pennsylvania: U.S. Geol. Survey Prof. Paper 282-F, p. 145-180.
Deevey, E. S., Jr., 1939, Studies on Connecticut lake sediments : Am. Jour. Sci., v. 237, no. 10, p. 691-724.

Gilbert, G. K., 1917, Hydraulic mining debris in the Sierra Nevada : U.S. Geol. Survey Prof. Paper 105, 154 p.

Horton, R. E., 1945, Erosional development of streams and their drainage basins-hydrophysical approach to quantitative morphology : Geol. Soc. America Bull., v. 56, p. 275-370.

Leopold, L. B., 1953, Downstream changes of velocity in rivers : Am. Jour. Sci., v. 251, no. 8, p. 606-624.

Leopold, L. B., and Langbein, W. B., 1962, The concept of entropy in landscape evolution: U.S. Geol. Survey Prof. Paper 500-A, p. 1-20.

Leopold, L. B., and Maddock, Thomas, Jr., 1953. Hydraulic geometry of stream channels and some physiographic implications: U.S. Geol. Survey Prof. Paper 252, 57 p.

Leopold, L. B., and Miller, J. P., 1956, Ephemeral streamshydraulic factors and their relation to drainage net: U.S. Geol. Survey Prof. Paper 282-A, p. 1-37.

Nixon, Marshall, 1959, A study of bankfull discharge of rivers in England and Wales: Inst. Civil Engineers Proc., v. 12, p. 157-174.

Pillsbury, G. B., 1939, Tidal hydraulics : Washington, U.S. Army Corps of Engineers, Prof. Paper 34, 281 p.

Wolman, M. G., and Leopold, L. B., 1957, River flood plains ; some observations on their formation: U.S. Geol. Survey Prof. Paper 282-C, p. 87-109.

Wolman, M. G., and Miller, J. P., 1960, Magnitude and frequency of forces in geomorphic processes: Jour. Geology, v. 68, no. 1, p. 54-74. 